\title{
MECHANICAL CHARACTERIZATION OF HISTORICAL MASONRY BY CORE DRILLING AND TESTING OF CYLINDRICAL SAMPLES
}

\author{
Luca Pelà $^{\mathrm{a}}$, Pere Roca ${ }^{\mathrm{a}}$, Andrea Benedetti ${ }^{\mathrm{b}}$ \\ ${ }^{a}$ Department of Construction Engineering, Technical University of Catalonia (UPC- \\ BarcelonaTech), Jordi Girona 1-3, 08034 Barcelona, Spain. \\ ${ }^{b}$ Department of Civil, Chemical, Environmental and Materials Engineering, University \\ of Bologna, Viale Risorgimento 2, 40136 Bologna, Italy.
}

\begin{abstract}
This paper presents an experimental study aimed at the characterization of the mechanical behaviour of existing masonry. The research proposes a methodology based on the in-situ core drilling of existing masonry members, made of clay brick and low-strength lime mortar. The obtained cylindrical samples, with different diameters, are tested in the laboratory to derive the compression and frictional response of the composite material and the components (units, mortar). The paper addresses the main issues related to the extraction of cylindrical specimens, the testing and the interpretation of results. The proposed minor destructive technique is suitable for existing masonry structures and especially for those of the built cultural heritage, since a direct estimation of the mechanical parameters can be obtained without damaging excessively the historical structure.
\end{abstract}

Keywords: Masonry, Lime Mortar, Coring, In-situ Sampling, Minor Destructive Testing (MDT), Brazilian Test, Compression Test, Mohr-Coulomb theory, Shear, Friction.

\section{Introduction}

The mechanical characterization of masonry is a difficult task due to the heterogeneous and composite character of the material. The properties of units, mortar and the

\footnotetext{
* Corresponding author.

E-mail addresses: 1uca.pela@upc.edu (Luca Pelà), pere.roca.fabregat@upc.edu (Pere Roca), andrea.benedetti@unibo.it (Andrea Benedetti).
} 
composite can be normally obtained in the laboratory by standard destructive experiments that have been devised for new structures.

The experiments proposed by the current standards are unfeasible in the case of existing buildings, due to the difficulties in extracting representative samples equivalent to the specimens required by regulations, e.g. in terms of dimensions, arrangement of components and integrity. The case of historical masonry is even more complex, since the structure cannot be excessively damaged during the in-situ sampling due to its cultural, historical and economical value. Several techniques were proposed to minimise the damage during the inspection, like in-situ non-destructive testing (NDT), providing indirect evaluation of materials' properties, or minor destructive testing (MDT), affecting the structural members only superficially or at least in limited portions (Binda et al. 2000). An interesting possibility is the extraction of samples to be subjected to destructive testing in the laboratory. The sampling procedure must inflict the lowest possible damage to the historical structure. The technique adopted is very important, since the specimens must be as undamaged as possible to be representative of the in-situ material. The extraction of mortar samples from the joints of a wall is difficult, since the material is brittle and usually crumbles as soon as it is removed from the original location. The sampling of wall portions, to evaluate the properties of the composite material, is almost impossible for existing historical structures.

Recent studies have shown the possibility of evaluating the mechanical behaviour of existing masonry by core drilling and subsequent mechanical testing of samples in the laboratory. Drilling is usually horizontal and perpendicular to the face of a structural member, like a wall. Benedetti and co-workers could derive the strength envelope of historical mortars by testing 70 to $110 \mathrm{~mm}$ masonry cores extracted from an existing building. Different Brazilian tests were carried out with variable inclinations of the diametral mortar joint interposed between two circular segments of brick (Benedetti and Pelà 2012, Pelà et al. 2012). The mortar joint can be subjected to different combinations of shear-compression stresses by varying the joint inclination, for instance from $45^{\circ}$ to $60^{\circ}$. This method takes the most advantage from this kind of specimen, since much more information can be obtained than in Brazilian tests executed maintaining the same inclination of the mortar joint, e.g. 45 (Braga et al. 1992, Filardi et al. 1996, Benedetti et al. 2008). Besides that, the sampling technique is really effective since the mortar joint keeps confined by two bricks, allowing the extraction of rather undisturbed mortar specimens. 
Another interesting testing technique on masonry cylindrical specimens is that proposed by the UIC 778-3 recommendations of the International Union of Railways (UIC, 1995). Compressive tests are performed on masonry cylinders with $150 \mathrm{~mm}$ diameter loaded on the lateral surface. The cylinder is centred in the middle of a vertical joint, so that the test is performed in the same direction in which the load is expected to act. The lateral surfaces are made regular by means of a lead sheet between the sample and the steel loading plates. The UIC 778-3 recommendations suggest that a minimum of three samples should be tested for each type of brickwork, but six should preferably be used where available. The method was used by Brencich and co-workers to evaluate the compression strength of clay brick masonry (Brencich et al. 2004, Brencich and Sterpi 2006, Bilello et al. 2007). The sampling technique is still a minor destructive one, since only a small portion of the structure is affected by the extraction, while the specimen is sufficiently complex to represent the interaction among units, horizontal and vertical mortar joints. The UIC 778-3 recommendations advise not to test smaller diameter cores to characterize the compression behaviour of masonry, since smaller specimens are suitable only for the identification of the brick's properties.

This paper presents the results of an experimental program carried out in the laboratory to calibrate the aforementioned sampling and testing techniques of masonry cylindrical specimens. Cores of $90 \mathrm{~mm}$ and $150 \mathrm{~mm}$ diameter were extracted from natural hydraulic lime mortar and clay brick walls built in the laboratory, by using a core drilling machine. Brazilian tests were carried out on $90 \mathrm{~mm}$ diameter specimens, varying the inclination of the diametral joint, to evaluate the failure envelope of mortar. Compression tests were carried out on $150 \mathrm{~mm}$ diameter specimens, after having regularised the curved surface of the specimen to create two planes parallel to the bed joints of the masonry (Pelà et al. 2014). Small cores of $35 \mathrm{~mm}$ diameter were also extracted from the units of the wall to evaluate the compression and tensile strengths of the bricks.

The sampling procedure is described together with the testing layout for each type of specimen. The mechanical interpretation of each test is presented. The results from the proposed non-standard tests are discussed and compared with those derived from conventional tests on the same materials, like tests on mortar prisms or compression tests on stack-bonded prisms. This is made to give a reference for a better calibration of the new tests and to provide a direct comparison between the results from standard and non-standard techniques. 
To the authors' knowledge, no other similar research has been proposed yet to calibrate the core drilling and testing of cylindrical masonry samples, made of clay bricks and low-strength lime mortar, in a controlled laboratory environment. This paper is intended to give a contribution to the development of minor destructive non-standard techniques for the determination of the mechanical behaviour of existing and historical masonry.

\section{Experimental Program}

The experimental investigation was carried out at the Laboratory of Structural Technology of the Technical University of Catalonia (UPC-BarcelonaTech). In the following, the characterization of materials, the preparation of specimens, the sampling procedure and the test setups are detailed.

\subsection{Materials}

The materials were chosen in order to reproduce those employed in historical masonry of low mechanical properties. Natural hydraulic lime (NHL) mortar without cement was used since this traditional material is frequent in historical masonry. The aggregate used was washed river sand with 0 to $5 \mathrm{~mm}$ diameter. The binder/sand volumetric ratio was $1: 3$, in order to provide a good representation of an ancient mortar.

The mortar flexural strength $\left(f_{\mathrm{mf}}\right)$ and compressive strength $\left(f_{\mathrm{mc}}\right)$ were measured according to EN 1015-11:1999 (CEN, 2006), respectively on three prismatic samples with dimensions $40 \times 40 \times 160 \mathrm{~mm}^{3}$ and on the 6 fragments produced by the flexural test. The six remaining pieces measured roughly $40 \times 40 \times 80 \mathrm{~mm}^{3}$ and were loaded with steel loading platens of $40 \times 40 \mathrm{~mm}^{2}$ (Figures 1a-b). The results obtained at 61 and 75 days from mortar pouring are reported in Table 1. Strength obtained from each specimen, together with average values and relevant coefficients of variations (CV), are detailed. As expected, the NHL mortar properties slightly improved with time due to curing and hardening phenomena. The mechanical parameters obtained for the two ages investigated can be considered representative of a typical low-strength historical lime mortar.

Hand-molded solid clay bricks with dimensions $276 \times 133 \times 43 \mathrm{~mm}^{3}$ were used for the construction of masonry specimens. The brick compressive strength $\left(f_{\mathrm{bc}}\right)$ was determined according to European standard EN 772-1:2000 (CEN, 2011) on three bricks, which were regularized by polishing of the two faces in contact with the plates of the load machine. The test was performed in the same direction as the load acts in the wall. The experimental strength values were normalized according to the procedure 
proposed by the standard to account for specimen size and shape effects. The normalized strength values are shown in Table 1 . The brick flexural strength $\left(f_{\text {bf }}\right)$ was also evaluated, making reference to the European standard EN 772-6:2001 (CEN, 2001).

Small cores of $35 \mathrm{~mm}$ diameter and $70 \mathrm{~mm}$ height (slenderness ratio of 2) were also extracted from the stretcher face of the units. This kind of specimen can be obtained from existing walls, by core drilling the unit horizontally from the vertical side of the member. The vertical core drilling of the bed face of units is normally unfeasible onsite, and would provide samples with slenderness ratio around 1, i.e. not ideal for eliminating the confinement effects of the loading platens during compression test. The small cores were subjected to compression and Brazilian tests (Figures 1c-d) to compare the results from non-standard cylindrical specimens with those obtained from the whole unit. Not being available any standard for Brazilian test on bricks, EN 12390-6:2000 (CEN, 2000) was used as a reference for the test layout. The experimental strengths obtained are reported in Table 1. Good agreement is found between compression strengths on units and cores. As expected, the values of indirect tensile strength $f_{\mathrm{bt}}$ obtained from Brazilian splitting tests are lower than flexural strengths $f_{\mathrm{bf}}$ on units, due to the different stress states induced by each test on the material.

\subsection{Masonry Specimens}

A wall with dimensions $1.5 \times 0.75 \times 0.276 \mathrm{~m}^{3}$ was built in Flemish bond (Figure 2a), using the same materials described before. The construction of the wall was intended to reproduce an existing wall made of NHL mortar and clay bricks, i.e. with low mechanical properties, as it is typical in historical masonry buildings. The wall was used in the research to simulate the in-situ extraction of $90 \mathrm{~mm}$ and $150 \mathrm{~mm}$ diameter cylindrical specimens in the laboratory.

The wall was built over a steel beam to ease its displacement during the following stages of the experimental campaign. A constant thickness of the mortar joints was maintained, as much as possible, around 10 to $15 \mathrm{~mm}$, as well as the horizontality of bricks layers. At the end of the construction, a regularization layer of mortar was poured over the wall, to permit the location of another steel beam. The top and bottom steel profiles were then connected by two low-tensioned bars, to confine the wall during the movements experienced during the experimental program.

After 28 days of curing, the wall was taken out of its storage and turned onto its larger face, see Figure 3a. A total of twenty-four cylindrical specimens were then extracted 
from the whole thickness of the wall using a core drilling machine, see Figure $3 \mathrm{~b}$. Three types of specimens were obtained (Figure 4): $150 \mathrm{~mm}$ diameter cores including two horizontal mortar joints, a vertical mortar joint, and four brick pieces, from now on called 3J (three-joint specimens); $150 \mathrm{~mm}$ diameter cores including two horizontal mortar joints and three brick pieces, from now on called 2J (two-joint specimens); 90 $\mathrm{mm}$ diameter cores with a mortar diametral joint interposed between two circular segments of brick, from now on called $1 \mathrm{~J}$ (one-joint specimens). The $1 \mathrm{~J}$ specimens were assigned to the Brazilian test with inclined mortar joint (Benedetti et al. 2008, Benedetti and Pelà 2012, Pelà et al. 2012) whereas both the $2 \mathrm{~J}$ and $3 \mathrm{~J}$ specimens were assigned to the compression test suggested by the UIC 778-3 recommendations (UIC, 1995). The 2J specimen is different from that requested by the technical recommendations since it does not have the vertical mortar joint, but it was considered intentionally in this research to assess the influence of the joints on the compression strength of the sample.

After the extraction, the $270 \mathrm{~mm}$ long cylindrical specimens were cut into two parts, obtaining two samples about $135 \mathrm{~mm}$ long. The $2 \mathrm{~J}$ and $3 \mathrm{~J}$ specimens were regularized with cement mortar caps, using a wooden mould especially designed (Figure 5a). The curved surface of the specimen is regularized to create two planes parallel to the bed joints of the masonry. In this way, a vertical compression can be applied over the regularization planes in order to reproduce on the sample the compression loading to which the wall is subjected. The purpose of this particular kind of regularization is also to ensure an optimal transmission of the compression force from the testing machine to the specimen through a perfectly adherent high-strength cap, in order to avoid any stress concentration. This novel solution for regularization is proposed as an alternative to the test layout suggested by the UIC 778-3 recommendations, which is based on the use of concave steel loading plates and lead sheets to regularize the contact with the specimen (Brencich et al. 2004, Brencich and Sterpi 2006, Bilello et al. 2007).

Twenty $1 \mathrm{~J}$ samples, six $2 \mathrm{~J}$ samples and five $3 \mathrm{~J}$ samples were used eventually to perform non-standard Brazilian and compressive tests. The best twenty $1 \mathrm{~J}$ samples were selected for testing. One $3 \mathrm{~J}$ sample and some $1 \mathrm{~J}$ samples were spoiled during the extraction. The core drill was water cooled and thus water sometimes washed mortar joints away.

Three stack-bonded prisms (Figure $2 b$ ) were also built at the same time of the construction of the wall and using the same materials. Each prism consisted of five stacked units separated by four mortar joints. The lowest and uppermost bricks were coated with a layer of high-strength cement mortar, to ensure the flatness of the loading 
surfaces, as established by EN 1052-1:1998 (CEN, 1999). Immediately after the construction, the prisms were covered with polyethylene sheets for three days in order to prevent premature drying out. The stack-bonded prisms were then kept in laboratory conditions until 61 days after construction.

\subsection{Testing setups}

The $2 \mathrm{~J}$ and $3 \mathrm{~J}$ cylindrical specimens were tested under compression according to the UIC 778-3 recommendations (UIC, 1995). The test procedure consisted in applying a compressive load on the regularization caps and perpendicular to the bed joints. Both the vertical and horizontal displacements were recorded through 4 LVDTs (Figure 5b) to assess the possibility of measuring the masonry Young's modulus and Poisson's ratio. Two vertical LVDTs were attached to the regularization caps and two horizontal LVDTs were fixed on two metal supports, along the diametral direction of the specimen. In all the tests the load was applied under displacement control, at a rate of $0.006 \mathrm{~mm} / \mathrm{s}$. The tests were conducted at 61 days after construction.

The three stack-bonded prisms were subjected to compression test (Figure 5c), in order to compare the results with those from cylinders. Six LVDTs were used to measure vertical and horizontal displacements, making reference to EN 1052-1:1998 (CEN, 1999). Five initial loading cycles under force control were executed in a range of load between $10 \mathrm{kN}$ and $100 \mathrm{kN}$. The test was then performed under displacement control in order to follow the post-peak response of the masonry. The displacement was applied at a rate of $0.003 \mathrm{~mm} / \mathrm{sec}$. The compression tests were conducted at the same age of those on cylinders, i.e. at 61 days.

Brazilian tests were carried out on $1 \mathrm{~J}$ specimens with varying the inclination of the diametral mortar joint (Benedetti and Pelà 2012, Pelà et al. 2012). Due to the novelty of this kind of test, no specific standards are available except for EN 12390-6:2000 (CEN, 2000) for splitting test of concrete. The test layout was the same as the one adopted by Benedetti and co-workers in the aforementioned references. The test consists in laying horizontally between the loading platens a masonry cylindrical specimen including two circular segments of brick and a diametral mortar joint. The specimen is compressed along two opposite longitudinal generators until failure (Figure 6). Two wood strips were inserted between the platens and the cores to distribute correctly the loading. The test was carried out under vertical displacement control at a rate of $0.005 \mathrm{~mm} / \mathrm{s}$. In this work, $1 \mathrm{~J}$ cores were tested with different inclinations of the mortar diametral joint with respect to the horizontal direction, denoted by angle $\alpha$ (Figure 6a). Different 
combinations of shear-compression stresses can be obtained by varying the joint inclination. Four cores were tested with $\alpha=0^{\circ}$, five cores with $\alpha=35^{\circ}$, six cores with $\alpha=45^{\circ}$ and five cores with $\alpha=55^{\circ}$. The angle $\alpha$ of inclination of the diametral joint determines the magnitude of the normal and tangential stresses applied on the mortar during the test. In particular, the increasing inclination from $\alpha=0^{\circ}$ to $\alpha=55^{\circ}$ causes an increase of the tangential shear component of the load on the mortar joint during the test, as well as decreases the transversal compression component.

\section{Experimental results and discussion}

This section presents the main outcomes of the experimental program. Firstly, the results of the compression tests on stack-bonded prisms and $150 \mathrm{~mm}$ diameter cores are compared to get a better interpretation of the non-standard test results on masonry cores. Secondly, the results of the Brazilian tests on $90 \mathrm{~mm}$ diameter cores are processed in order to obtain the strength envelope of the lime mortar. Finally, the critical discussion of results leads to some relevant conclusions about the experimental methodology and issues deserving further investigation.

\subsection{Compression tests on stack-bonded prisms and cylindrical samples}

The stack-bonded prisms were tested under initial loading and unloading cycles, showing stiffening behaviour due to micro-cracks and voids closure in mortar. Then, the samples were loaded until failure. Table 2 reports the compressive strength $\left(f_{c}\right)$ obtained from the compression tests on stack-bonded prisms. The samples showed mainly vertical cracks after testing, as expected (Figures 7a-b). Mortar expansion at the edges of joints could be clearly observed during the test, as well as vertical cracks through the units. The regularization cement mortar proved to be suitable, as it was demonstrated by its normally undamaged state at the end of the test.

Both the $3 \mathrm{~J}$ and $2 \mathrm{~J}$ specimens exhibited the same failure mode upon compression testing, according to a sandglass shape (Figure 8). Two concave symmetrical cracks, almost aligned with the edges of the upper and lower regularization caps, are the prelude to the failure of the samples. At the end of the test, the remaining part of the specimens was sandglass shaped, with upper and lower sections equal to those of the regularization caps. Micro-cracks were distributed throughout the damaged specimens. The regularization mortar caps were intact at the end of most of the test. Few specimens experienced the local detachment of a superficial edge of the regularization cap due to 
the sudden propagation of the aforementioned concave lateral crack (Figure 8a). The sandglass shape and the detachment of the lateral portions of the samples at failure were also observed in previous studies (Brencich et al. 2004, Brencich and Sterpi 2006, Bilello et al. 2007). Such type of failure is due to the lower confinement to which the lateral parts of the sample are subjected, since the width of the regularization caps is lower than the diameter of the cylinder.

A summary of the main results obtained from compression tests on $3 \mathrm{~J}$ and $2 \mathrm{~J}$ cylindrical specimens is reported in Table 2, in terms of ultimate load and strength.

Whereas the calculation of the experimental compression strength in prisms is straightforward, the compression strength of cylinders must be evaluated carefully making reference to the peculiar mode of failure observed. The UIC 778-3 recommendations (UIC 1995) propose to calculate the compressive strength of masonry from cylindrical specimens as the ratio between the maximum load $F_{\max }$ and the horizontal cross-section $\phi \cdot l$, being $\phi$ the diameter and $l$ the length of the cylinder. Applying this method, the entire horizontal cross-section of the specimen is considered as resistant until reaching the maximum load. However, the experimental evidence from the current research showed that the specimens experienced cracking and subsequent detachment of the lateral less confined parts of the specimens. This is due to the diffusion of compression stresses from the smaller caps to the larger central horizontal section that causes transversal tensile stresses. After cracking, the compression stresses concentrate in a sand cone shape in the central part of the specimen. Therefore, the effective resistant cross-section of the sample may be smaller than the total horizontal one.

In this paper, two different evaluations of the compression strength have been considered. The first one, denoted by $f_{\mathrm{C} 1}$, is calculated with reference to the whole horizontal section of the cylindrical specimen, i.e. according to the UIC 778-3 recommendations. The second one, denoted by $f_{\mathrm{C} 2}$, is proposed in this research making reference to the section of the regularization cap. The relevant expressions are:

$$
f_{C 1}=\frac{F_{\max }}{\phi l} \quad f_{C 2}=\frac{F_{\max }}{b l}
$$

in which $b$ is the width of the mortar caps.

Table 2 reports the values of $f_{\mathrm{C} 1}$ and $f_{\mathrm{C} 2}$ obtained during the compression tests on the $3 \mathrm{~J}$ and $2 \mathrm{~J}$ specimens. The average compressive strength obtained for $2 \mathrm{~J}$ specimens resulted always higher than that of $3 \mathrm{~J}$ specimens $(+18 \%$ in the average). This is due to the 
absence of the vertical mortar joint. The width of head joints in $3 \mathrm{~J}$ samples was about 15 $\mathrm{mm}$, therefore non-negligible if compared to the resistant cross-section. In addition, the presence of the head joint in 3J samples forced the compression stresses to diffuse wider than in $2 \mathrm{~J}$ ones, generating higher transversal tensile stresses that reduce the experimental compression strength.

The average value of the compression strength $f_{\mathrm{Cl}}$ obtained by testing $3 \mathrm{~J}$ cylinders $(6.84$ $\mathrm{MPa})$ is $21 \%$ lower than that from the standardized test on stack-bonded prisms $(8.64$ $\mathrm{MPa}$ ). On the contrary, the average value of compression strength $f_{\mathrm{C} 1}$ determined by testing the $2 \mathrm{~J}$ cylinders $(8.10 \mathrm{MPa})$ is closer to the value obtained from the stack-bonded prisms $(-6 \%)$. When the section of the regularization cap is considered in calculations, the average value of compression strength $f_{\mathrm{C} 2}$ obtained by testing $3 \mathrm{~J}$ specimens $(8.55$ $\mathrm{MPa})$ is very similar to that of the standardized test on stack-bonded prisms $(-1 \%)$. On the contrary, the average value of compression strength $f_{\mathrm{C} 2}$ determined by testing $2 \mathrm{~J}$ specimens $(10.12 \mathrm{MPa})$ is $17 \%$ higher than the value obtained from stack-bonded prisms.

The equation provided by the Eurocode 6 (CEN 2005) to evaluate the compressive strength of masonry would provide a characteristic value of $6.11 \mathrm{MPa}$, considering the experimental mean values of the compressive strengths of units and mortar at 61 days after construction (Table 1). This value can be compared with the experimental characteristic ones that have to be determined taking into account the limited number of samples (Italian Ministry of Infrastructure and Transport 2008). The value predicted by the Eurocode 6 tends to underestimate the characteristic values of the experimental compression strengths of stack-bonded prisms and cores (Table 2), with the only exception of $f_{\mathrm{C} 1}$ for $3 \mathrm{~J}$ samples.

As mentioned in Section 2.3, the tests were carried out under displacement control and with LVDTs instruments, in order to assess the possibility of measuring the Young's modulus and Poisson's ratio of masonry. The UIC 778-3 recommendations advise against deriving information about material deformability from this test, due to the material inhomogeneity. However, previous studies (Brencich et al. 2004, Brencich and Sterpi 2006, Bilello et al. 2007) attempted to evaluate the Young's modulus by considering a reduced section $0.75 \cdot \phi \cdot l$ in stress calculations and making reference to the loads at $1 / 10$ and $1 / 2$ of the maximum load. This approach provided very low values of Young's modulus and widely scattered values of Poisson's ratio. The attempt made in this research also provided low and scattered Young's moduli. The evaluation of 
Poisson's ratio also showed a large scatter of results. Therefore, both this research and previous ones encountered similar complexities in the assessment of the deformation properties of the cylindrical specimens. Regarding the Young's modulus, it is worth mentioning that in both cases the specimens were not stabilized by preliminary loading and unloading cycles and this might be the reason of unreliable and scattered experimental outcomes. An ongoing research project at the Technical University of Catalonia is addressing the aforementioned issues and trying to improve the experimental setup.

\subsection{Brazilian tests on $90 \mathrm{~mm}$ diameter cylindrical specimens}

A summary of the experimental results from Brazilian tests on $1 \mathrm{~J}$ cylindrical specimens is reported in Tables 3,4,5,6, both in terms of ultimate loads and failure modes. As shown, the ultimate load $F_{\max }$ decreases as the inclination of the mortar joint increases, viz. from an average ultimate load of $18.57 \mathrm{kN}$ for $0^{\circ}$ until $7.66 \mathrm{kN}$ for $55^{\circ}$. This is due to the increasing ratio between shear and normal stresses acting on the mortar joint as the inclination angle increases. In fact, the stress components normal and tangential to the mortar joint at failure can be expressed by the following expressions (Benedetti and Pelà 2012, Pelà et al. 2012):

$$
\sigma_{\max }=\frac{F_{\text {max }}}{\phi l} \cos \alpha \quad \tau_{\max }=\frac{F_{\text {max }}}{\phi l} \sin \alpha
$$

where $\sigma_{\max }$ and $\tau_{\max }$ are the compression and shear stresses on the mortar joint at failure, and $\alpha$ is the inclination of the diametral mortar joint of the core, with respect to the horizontal direction, during the Brazilian test. The values of $\sigma$ and $\tau$ are reported in Tables 4,5,6 for inclinations $\alpha>0$.

For $\alpha=0$, Table 3 reports instead the tensile strength computed according to the wellknown expression for the split-cylinder test (Chen 1975):

$$
f_{t}=\frac{2 F_{\max }}{\pi \phi l}
$$

The average value obtained for $f_{\mathrm{t}}$ is $0.95 \mathrm{MPa}$, corresponding to one ninth of the average compression strength of the prisms.

The failure mode also changes by varying the inclination of the mortar joint. For $0^{\circ}$, the failure mode is given by splitting across a vertical diameter plane together with a horizontal fracture involving mortar and brick-mortar interface. For $\alpha=35^{\circ}$, the failure is 
given by combined splitting and fracture involving the mortar and the brick-mortar interface. For $\alpha=45^{\circ}$, the fracture crosses the mortar joint at the core centre and involves the upper and lower brick-mortar interfaces at the sample extremities. In addition, the specimen exhibits brick wedge detachment close to the upper load. For $\alpha=55^{\circ}$, the failure mode is equivalent to the $\alpha=45^{\circ}$ one, but in four out of five specimens the fracture is localized in the mortar joint, with only one specimen showing the brick wedge detachment close to the upper load.

On the basis of the aforementioned comments, one can conclude that although for $\alpha=35^{\circ}$ the failure is mixed and involves both the joint and the units, for inclinations starting from $\alpha=45^{\circ}$ we can recognize a clear characteristic failure mode for this kind of test. The fracture involves mainly the joint, crossing the mortar in the centre of the core and propagating towards the extremities along the upper and lower interfaces. The same failure mode was observed in previous studies on the Brazilian test on cores with inclined mortar joint (Braga et al. 1992, Filardi et al. 1996, Benedetti et al. 2008, Benedetti and Pelà 2012, Pelà et al. 2012). In turn, both the specimen and the fracture mode can be termed as "parasymmetric", according to the definition provided by Pozzati (1972), or "centrally symmetric", since they can be reproduced by rotating of $180^{\circ}$, after having cut along the vertical diametral plane, one half of the sample and then joining the two halves together. In other words, every point in the sample, either fractured or not, has a matching point at the same distance from the centre but in the opposite direction, as shown in Figure 9.

The results of the Brazilian tests with varying inclination of the joint interposed between two brick circular segments can be used to build the failure envelope of the mortar. In fact, every test with different joint inclination $\alpha \geq 45^{\circ}$ is able to represent the failure of mortar subjected to a different combination of shear-compression stresses. The frictional failure envelope of mortar is represented by the straight-line with equation:

$|\tau|=c-\sigma \tan \phi$

where $c$ is the cohesion and $\phi$ is the internal friction angle of the mortar. These two parameters are necessary to define the failure envelope of mortar, viz. to fully characterize its frictional behaviour.

From a general point of view, two interpretative models are possible to describe the experimental results from Brazilian tests on $1 \mathrm{~J}$ cores with inclined mortar joint: 
i) Continuum model: the specimen's ultimate condition is due to the shear failure of the material composing the joint. Its stress state at failure is represented by a Mohr's circle in the $\sigma-\tau$ Mohr's plane, whose construction is shown in Figure 10a. The failure envelope is the straight-line of Equation 4 that shall be tangent to all the ultimate Mohr's circles of all tested specimens. Due to experimental scattering, it is necessary to adjust the parameters $c, \phi$ of the envelope line to best fit the experimental data set. To do that, the least squares method is used to minimize the sum of square residuals $V_{\mathrm{i}}$ :

$$
\min \left\{\sum_{i} V_{i}^{2}\right\}=\min \left\{\sum_{i}\left(D_{i}-R_{i}\right)^{2}\right\}
$$

where the residual $V_{\mathrm{i}}$ is the difference between the distance $D_{\mathrm{i}}$ of the centre of the $i$-th Mohr's circle from the sought failure line and the radius $R_{\mathrm{i}}$ of the $i$-th Mohr's circle, see Figure $10 \mathrm{~b}$. Note that whereas $R_{\mathrm{i}}$ only depends on the $i$-th experimental result, $D_{\mathrm{i}}$ also depends on the sought parameters $c$ and $\phi$. Making reference to Figure 10, the function to be minimized can be finally expressed as:

$$
\min \left\{\sum_{i}\left[\left(\frac{c}{\tan \phi}-\frac{\sigma_{\max , i}}{2}\right) \sin \phi-\sqrt{\frac{\sigma_{\text {max }, i}^{2}}{4}+\tau_{\text {max }, i}^{2}}\right]^{2}\right\}
$$

where $\sigma_{\max , i}$ and $\tau_{\max , i}$ are provided by Equations (2a,b) for each $i$-th tested sample.

ii) Interface model: the specimen's ultimate condition is due to the shear sliding on the joint interface. The stress state of each $i$-th specimen at failure is represented by a point in the $\sigma-\tau$ plane whose coordinates $\left(\sigma_{\mathrm{i}}, \tau_{\mathrm{i}}\right)$ are provided by Equations $(2 \mathrm{a}, \mathrm{b})$. The failure envelope is the straight-line of Equation 4 obtained by simple linear regression through the set of $\left(\sigma_{\mathrm{i}}, \tau_{\mathrm{i}}\right)$ points.

Figure 11 shows the failure envelope obtained by the continuum model. The drawn Mohr's circles represent the ultimate stress states of mortar in the Brazilian tests with $\alpha=45^{\circ}$ and $\alpha=55^{\circ}$. The figure also depicts the Mohr's circles related to the ultimate stress states of mortar prisms tested under uniaxial compression. The continuum model, in fact, allows for the combination of different testing methods to evaluate the failure envelope of mortar. Execution and comparison of different testing techniques is highly advisable during the mechanical characterization of existing materials. The Mohr's circles of the compression tests are tangent to the $\sigma=0$ axis assuming a uniaxial stress state in the sample. The Mohr's circles referring to specimens with $\alpha=35^{\circ}$ have been 
neglected due to their mixed failures exhibited upon testing, which involved cracking across the bricks. The points on the failure envelope closest to the Mohr's circles, i.e. minimizing the scatter $V_{\mathrm{i}}$, are also drawn. The least squares procedure provides the following Mohr-Coulomb parameters: $\phi=27.1^{\circ}$ and $c=0.62 \mathrm{MPa}$. According to the Mohr-Coulomb theory, it is also possible to derive the compression and tensile strength of the mortar by using the following expressions:

$$
f_{m c}=\frac{2 c \cos \phi}{1-\sin \phi} \quad f_{m t}=\frac{2 c \cos \phi}{1+\sin \phi}
$$

By using Equations $(7 \mathrm{a}, \mathrm{b})$ we obtain $f_{\mathrm{mc}}=2.01 \mathrm{MPa}$ and $f_{\mathrm{mt}}=0.75 \mathrm{MPa}$, that are in remarkable agreement with the strength values obtained by standard testing on mortar prisms (Table 1), proving the consistency of the continuum model for the mechanical characterization of mortars. The continuum interpretative model allows us to derive the compressive, tensile and shear strength parameters of mortar from the Brazilian test of cores with inclined mortar joint. In addition, the continuum model is consistent with the "parasymmetric" mode of failure of the specimens, describing correctly the failure of the mortar material in the centre of the cylindrical specimen. This interpretative approach seems suitable for the typical historical low-strength lime mortars.

Figure 12 shows the failure envelope obtained by the interface model. The simple linear regression through the experimental data set provides the following Mohr-Coulomb parameters: $\phi=31.9^{\circ}$ and $c=0.29 \mathrm{MPa}$. Compared to the continuum model, the internal friction angle is higher $(+11 \%)$ whereas the cohesion is lower $(-52 \%)$. Note that this approach interprets the specimen's failure as a shear sliding along an interface. Therefore, the interface model looks less appropriate to describe the experimental failure of masonry cores with low-strength lime mortar, typical of historical construction. This kind of interpretative theory seems more appropriate for newer masonry with either cement mortar or mixed lime-cement mortar. In fact, in case of higher strength mortar, the failure mode is not the aforementioned "parasymmetric" one but the pure sliding along the brick-mortar interface.

Note also that the interface model allows us to estimate neither the compression nor the tensile strength of mortar, and the Equations $(7 \mathrm{a}, \mathrm{b})$ cannot be used from a theoretical point of view since they correspond to a different concept. 


\section{Conclusions}

This paper has presented an experimental program aimed at calibrating a novel MDT technique based on in-situ core drilling and subsequent testing of masonry cylindrical specimens. A wall was built in the laboratory using hand-molded solid clay bricks and natural lime mortar (without cement), in order to represent a typical historical masonry. The following types of cylindrical samples were core drilled from the wall: $90 \mathrm{~mm}$ diameter cores with one diametral mortar joint (1J), $150 \mathrm{~mm}$ diameter cores with two mortar joints (2J) and $150 \mathrm{~mm}$ diameter cores with three mortar joints (3J). Small cores of $35 \mathrm{~mm}$ diameter were also extracted from the units of the wall. On the basis of the results derived from the experimental tests on the aforementioned samples, the following conclusions can be drawn:

- The materials used in the experimental program have shown to be representative for historical masonry, with compression strength of bricks around $25 \mathrm{MPa}$ and of mortar around $1.9 \mathrm{MPa}$ (after 75 days of curing).

- Testing of $35 \mathrm{~mm}$ diameter brick cores has provided reliable results if compared with standard tests on units. The in-situ core drilling of units can be considered a suitable MDT technique for the mechanical characterization of historical bricks.

- Standard tests on stack-bonded prisms have shown that satisfactory masonry strength can be obtained using conventional NHL mortars and moderately strong units. The obtained average compression strength of $8.64 \mathrm{MPa}$ is 5.4 times higher than the compressive strength of the mortar, at only 61 days of curing.

- The compression test on $150 \mathrm{~mm}$ diameter cores proposed by the UIC 778-3R (UIC, 1995) has shown to be a suitable technique to evaluate the compressive strength of existing masonry. Some improvements to the test layout have been proposed in this paper, like the regularization of the lateral surfaces of the cylindrical specimens by highstrength mortar capping instead of concave steel loading plates, in order to simplify the preparation of specimens and to avoid local stress concentrations during testing.

- Besides the $3 \mathrm{~J}$ specimen suggested by the UIC 778-3R guidelines, this research has also considered a $2 \mathrm{~J}$ specimen without head joint, to assess its effect on the strength of the $150 \mathrm{~mm}$ diameter sample. The $2 \mathrm{~J}$ specimens have provided an average compressive strength $18 \%$ higher than the $3 \mathrm{~J}$ specimens' one, showing that the absence of the vertical mortar joint increases the load bearing capacity of the cylindrical sample.

- The nonstandard compression tests of 3J and 2J cylindrical specimens have provided strength values in good agreement with those derived from standard tests on stack- 
bonded prisms. However, the compressive strength of cylindrical specimens should be evaluated carefully. In this research, when evaluated on the entire horizontal crosssection of the specimen $\phi \cdot l$, as suggested by the UIC $778-3 \mathrm{R}$ guidelines, the average compression strength of $3 \mathrm{~J}$ specimens resulted $21 \%$ lower than the stack-bonded prisms' one, whereas the compression strength of $2 \mathrm{~J}$ specimens was only $6 \%$ lower. This study has also proposed an alternative evaluation of the compression strength, by considering the resisting cross-section equal to that given by the regularization caps. This interpretation is suggested by the typical sandglass shape exhibited by the specimens at failure. In this case, the average compression strength of $3 \mathrm{~J}$ specimens resulted only $1 \%$ lower than the stack-bonded prisms' one, whereas the compression strength of $2 \mathrm{~J}$ specimens resulted $17 \%$ higher.

- The Brazilian tests on $90 \mathrm{~mm}$ diameter $1 \mathrm{~J}$ specimens have shown that if the diametral mortar joint is kept horizontal during testing $\left(\alpha=0^{\circ}\right)$, information can be derived about the tensile strength of masonry. On the other hand, different Brazilian tests on cores with inclinations of joints $\alpha \geq 45^{\circ}$ can be considered to evaluate the frictional failure envelope of the mortar. The specimens tested with $\alpha=45^{\circ}$ and $\alpha=55^{\circ}$ have shown a typical "parasymmetric" or "centrally symmetric" mode of failure, with a fracture crossing the mortar joint at the core's centre and involving the upper and lower brickmortar interfaces at the sample extremities.

- The Brazilian tests with variable inclination of the mortar joints for $\alpha \geq 45^{\circ}$ induce different combinations of shear and compression stresses on the mortar joint. The experimental results can be combined to draw the failure envelope of the mortar. Two interpretative theories have been proposed in this paper: the continuum model, representing the specimens' stress state at failure by Mohr's circles and the interface model, representing the specimens' stress state at failure by points. Using a least squares method and a simple linear regression, respectively, it is possible to draw the failure envelope of the mortar joint. The first approach considers the shear failure of the material composing the joint, whereas the second one considers the shear sliding along the interface.

- The continuum interpretative model seems more consistent with the "parasymmetric" type of failure evidenced by the Brazilian tests, i.e. the shear failure of the low-strength mortar material in the centre of the core. Also, the continuum model can combine different testing methods in the same theoretical framework: Brazilian tests can be integrated with mortar compression tests or many other testing layouts, looking for that 
redundancy of results that is highly advisable in the mechanical characterization of existing materials. In this research, the continuum model has provided the MohrCoulomb parameters $\phi=27.1^{\circ}$ and $c=0.62 \mathrm{MPa}$, which predict tensile and compression strengths for mortar in remarkable agreement with the values obtained by standard testing on prisms.

- The interface model has provided $\phi=31.9^{\circ}$ and $c=0.29 \mathrm{MPa}$. This kind of interpretative theory seems more adequate for good strength mortars, like those adopted in newer masonry with cement, since it describes better the shear sliding over the brickmortar interface. This approach cannot combine different testing methods and cannot provide any information about the tensile and compressive strength of mortar.

- The standard core drilling procedure in presence of water, usually adopted in reinforced concrete construction, has revealed some limitations in this research. In fact, some specimens were spoiled during the extraction, since water washed some lime mortar joints away. The wet extraction seems more appropriate for new masonry with mortar including cement. An ongoing research project at the Technical University of Catalonia is calibrating a dry core drilling technique to improve the efficiency of the extraction procedure, in order to avoid the premature damaging of cores and decomposition of mortar joints during sampling.

- Even if a wider experimental database is necessary to derive more general conclusions, the MDT experimental technique proposed in this paper has shown its appropriateness, both in terms of results reliability and limited invasivity. All these features make it suitable for the mechanical characterization of historical masonry of the built cultural heritage.

\section{Acknowledgments}

This research has received the financial support from the MINECO (Ministerio de Economia y Competitividad of the Spanish Government) and the ERDF (European Regional Development Fund) through the MICROPAR project (Identification of mechanical and strength parameters of structural masonry by experimental methods and numerical micro-modelling, ref num. BIA2012-32234). The authors would like to thank Alice Peverini, Juan Carlos Witt, Cristina Usan and Lucía Garijo for their helpful contributions. 


\section{References}

Benedetti, A., Pelà, L., and Aprile, A. 2008. Masonry properties determination via splitting tests on cores with a rotated mortar layer. In Proceedings of 8th International Seminar on Structural Masonry, ed. B. Sinha and L. Tanaçan, 647-655. Istanbul: Istanbul Technical University.

Benedetti, A., and Pelà, L. 2012. Experimental characterization of mortar by testing on small specimens. In Proceedings of 15th International Brick and Block Masonry Conference, ed. H.R. Roman and G.A. Parsekian, 1-10, Florianòpolis: UFSC.

Bilello, C., Brencich, A., Corradi, C., Di Paola, M., and Sterpi, E. 2007. Experimental tests and theoretical issues for the identification of existing brickwork. In Proceedings of 10th North American Masonry Conference, 946-956. St. Louis: The Masonry Society.

Binda, L., Saisi, A., and Tiraboschi, C. 2000. Investigation procedures for the diagnosis of historic masonries. Construction and Building Materials, 14: 199-233.

Braga, F., Dolce, M., Filardi, B., Masi, A., Nigro, D. 1992. A Test Method to Assess the Shear Strength of Existing Masonry Structures - Theoretical Basis and First Experimental Results. In Proceeding of the International Workshop on Effectiveness of Injection Techniques for Retrofitting of Stone and Brick Masonry Walls in Seismic Areas, ed. L. Binda, 207-227, Milano: CNR-GNDT.

Brencich, E., Corradi, C., and Sterpi, E. 2004. Experimental approaches to the compressive response of solid clay brick masonry. In Proceedings of the 13th International Brick and Block Masonry Conference, ed. D. Martens, A. Vermeltfoort, 1-10. Amsterdam: Eindhoven University of Technology.

Brencich, E., and Sterpi, E. 2006. Compressive Strength of Solid Clay Brick Masonry: Calibration of Experimental Tests and Theoretical Issues. In Proceedings of 5th International Conference on Structural Analysis of Historical Constructions, ed. P.B. Lourenço, P. Roca, C. Modena, S. Agrawal, 757-765. New Delhi: Macmillan India Ltd.

CEN- European Committee for Standardization, 1999. EN 1052-1:1998 - Methods of test for masonry - Part 1: Determination of compressive strength. Brussels: CEN.

CEN - European Committee for Standardization, 2006. EN 1015-11:1999 - Methods of test for mortar masonry - Part 11: Determination of flexural and compressive strength of hardened mortar. Brussels: CEN.

CEN - European Committee for Standardization. 2011. EN 772-1:2000 - Methods of test for masonry units - Part 1: Determination of the compressive strength. Brussels: CEN. 
CEN- European Committee for Standardization, 2001. EN 772-6:2001 - Methods of test for masonry units - Part 6: Determination of bending tensile strength of aggregate concrete masonry units. Brussels: CEN.

CEN- European Committee for Standardization, 2000. EN 12390-6:2000 - Testing hardened concrete - Part 6: Tensile splitting strength of test specimens. Brussels: CEN.

CEN- European Committee for Standardization, 2005. EN 1996-1-1:2005 - Eurocode 6: Design of masonry structures - Part 1-1: General rules for reinforced and unreinforced masonry structures. Brussels: CEN.

Chen W.F. 1975. Limit analysis and soil plasticity. Amsterdam: Elsevier.

Filardi, B., Liberatore, D., Masi, A., and Nigro, D. 1996. Valutazione della resistenza a taglio di una tipologia muraria tramite prove su pannelli, carote e triplette (in Italian). In Atti del convegno nazionale "La meccanica delle murature tra teoria e progetto”, 75-84, Bologna: Pitagora Editrice.

Italian Ministry of Infrastructure and Transport. 2008. Decreto Ministeriale 14/01/2008: Norme Tecniche per le Costruzioni (in Italian). Rome: Ministero delle Infrastrutture e dei Trasporti.

Pelà, L., Benedetti, A., and Marastoni, D. 2012. Interpretation of experimental tests on small specimens of historical mortars. In Proceedings of 8th International Conference on Structural Analysis of Historical Constructions, ed. J. Jasieńko, 716-723. Wroclaw: DWE.

Pelà, L., Peverini, A., Garijo, L., and Roca, P. 2014. Experimental calibration of in-situ sampling and testing of historical masonry. In Proceedings of 9th International Conference on Structural Analysis of Historical Constructions, ed. F. Peña and M. Chávez, 1-12, Mexico City: UNAM.

Pozzati P. 1972. Teoria e Tecnica delle Strutture - Volume primo: Preliminari e Fondamenti (in Italian). Torino: UTET.

UIC - International Union of Railways, 1995. Leaflet 778-3R, Recommendations for the inspection, assessment and maintenance of masonry arch bridges. Paris: UIC.

\section{Figures Captions}

Figure 1 - Characterization of component materials: a) flexure and b) compression tests on mortar prisms; c) splitting and d) compression tests on brick cylindrical specimens.

Figure 2 - Masonry specimens built in the laboratory with natural hydraulic lime mortar and clay bricks: a) wall and b) stack-bonded prisms. 
Figure 3 - Extraction of cylindrical samples from the wall: core drilling (a) and wall after sampling (b).

Figure 4 - Cylindrical samples obtained from core drilling: a) $150 \mathrm{~mm}$ diameter twojoint specimen (2J), b) $150 \mathrm{~mm}$ diameter three-joint specimen (3J) and c) $90 \mathrm{~mm}$ diameter one-joint specimen (1J).

Figure 5 - Regularization of a $150 \mathrm{~mm}$ diameter core by cement mortar caps (a). Compression test setups for $3 \mathrm{~J}$ and $2 \mathrm{~J}$ cores (b) and stack-bonded prisms (c).

Figure 6 - Brazilian test of $1 \mathrm{~J}$ cores: a) layout and b) experimental setup.

Figure 7 - Compression tests on stack-bonded prisms: a-b) cracking in specimen SP2 at failure.

Figure 8 - Compression tests on $150 \mathrm{~mm}$ diameter cores: a) 3J sample and b) 2J sample after failure.

Figure 9 - The "parasymmetric" mode of failure showing central symmetry, in the Brazilian tests on $1 \mathrm{~J}$ cores.

Figure 10 - Interpretation of Brazilian tests on $1 \mathrm{~J}$ cores: a) construction of Mohr's circle representing the stress state of mortar at failure and b) least squares method used in the continuum interpretative model to evaluate the failure envelope.

Figure 11 - Interpretation of Brazilian tests on 1J cores: failure envelope obtained by the continuum model $\left(\phi=27.1^{\circ}\right.$ and $\left.\mathrm{c}=0.62 \mathrm{MPa}\right)$.

Figure 12 - Interpretation of Brazilian tests on 1J cores: failure envelope obtained by the interface model $\left(\phi=31.9^{\circ}\right.$ and $\left.\mathrm{c}=0.29 \mathrm{MPa}\right)$.

\section{Tables Captions}

Table 1 - Experimental strengths of NHL mortar prisms, brick units and brick cores.

Table 2 - Experimental results of compression tests on stack-bonded prisms, 3J and $2 \mathrm{~J}$ cylindrical specimens.

Table 3 - Experimental results of Brazilian tests on $1 \mathrm{~J}$ cylindrical specimens: $\alpha=0^{\circ}$.

Table 4 - Experimental results of Brazilian tests on $1 \mathrm{~J}$ cylindrical specimens: $\alpha=35^{\circ}$.

Table 5 - Experimental results of Brazilian tests on $1 \mathrm{~J}$ cylindrical specimens: $\alpha=45^{\circ}$.

Table 6 - Experimental results of Brazilian tests on $1 \mathrm{~J}$ cylindrical specimens: $\alpha=55^{\circ}$. 

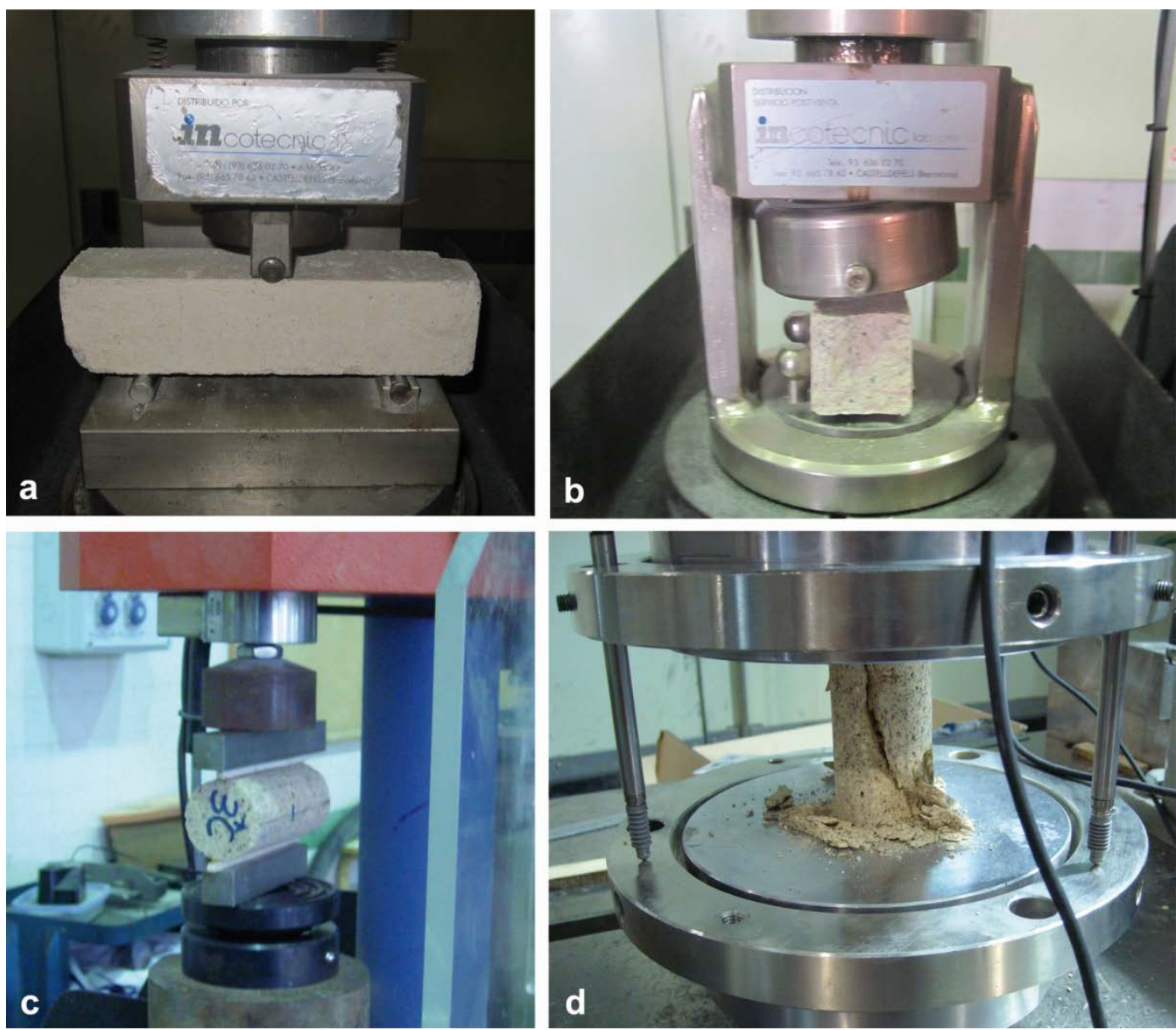

Figure 1 - Characterization of component materials: a) flexure and b) compression tests on mortar prisms; c) splitting and d) compression tests on brick cylindrical specimens.
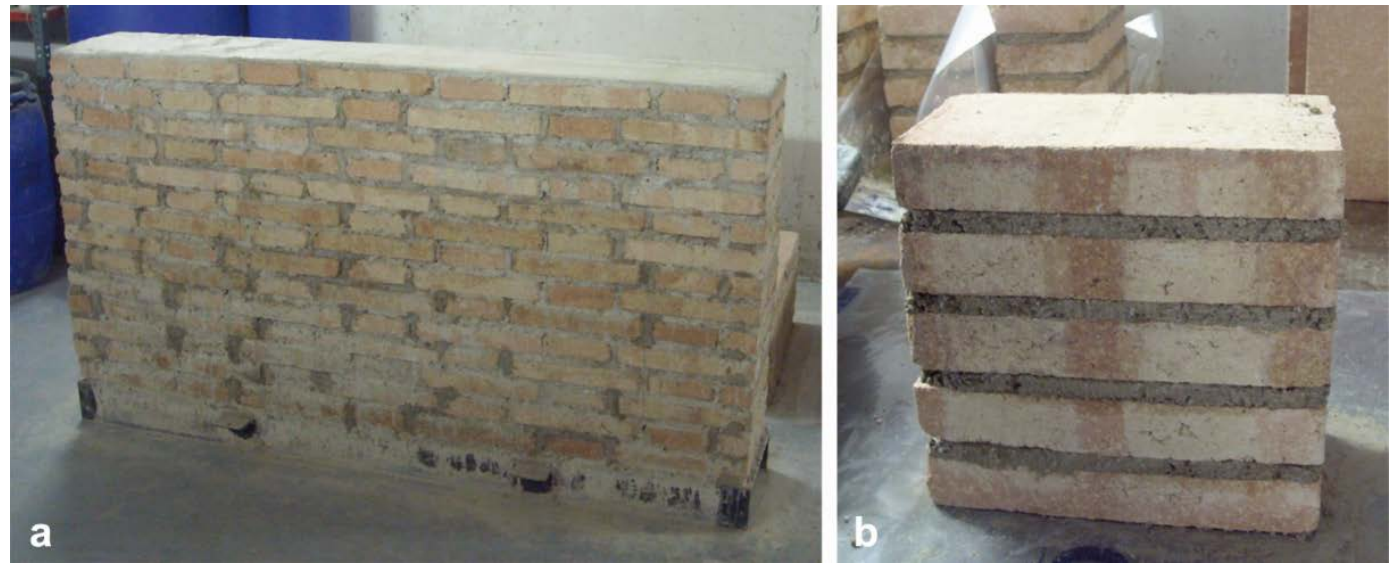

Figure 2 - Masonry specimens built in the laboratory with natural hydraulic lime mortar and clay bricks: a) wall and b) stack-bonded prisms. 

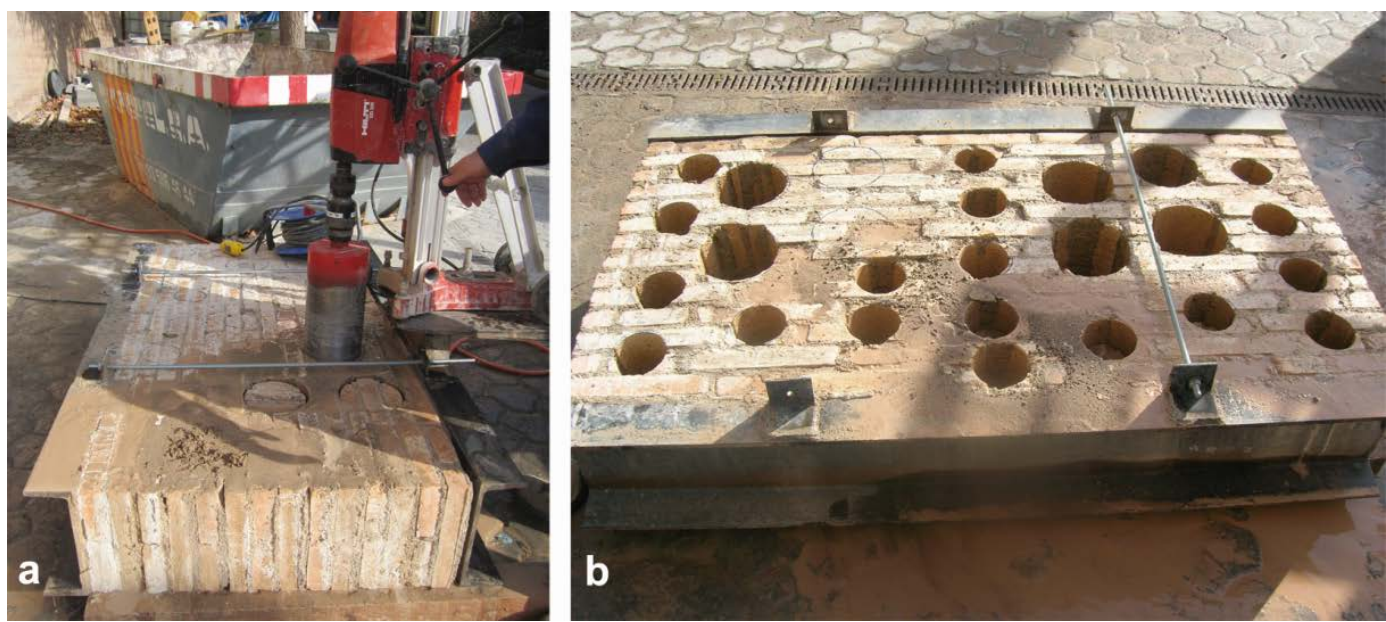

Figure 3 - Extraction of cylindrical samples from the wall: core drilling (a) and wall after sampling (b).
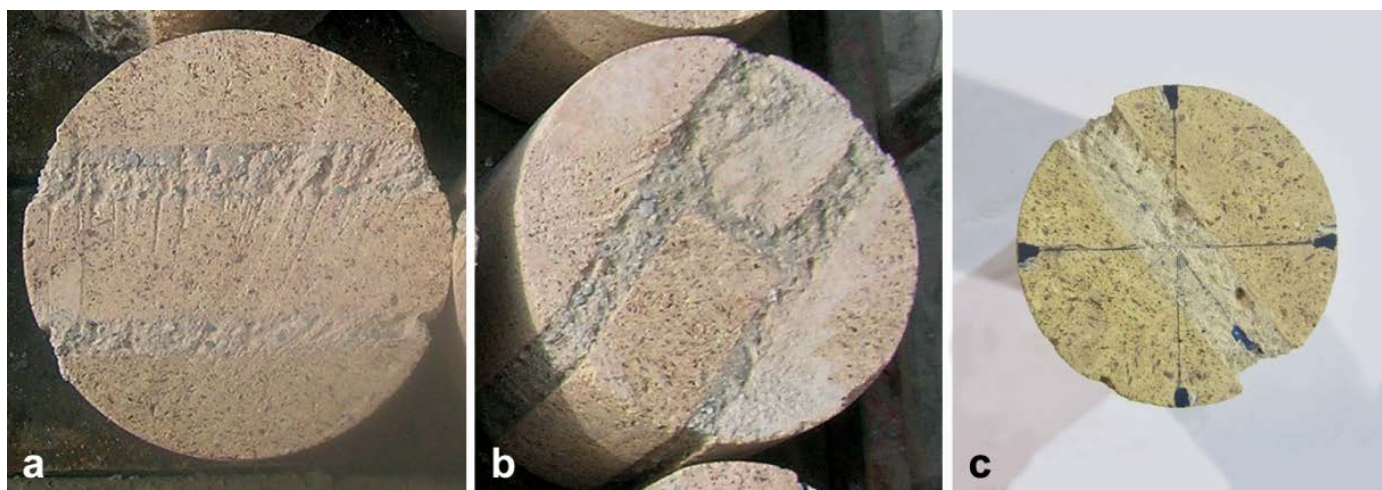

Figure 4 - Cylindrical samples obtained from core drilling: a) $150 \mathrm{~mm}$ diameter two-joint specimen (2J), b) $150 \mathrm{~mm}$ diameter three-joint specimen (3J) and c) $90 \mathrm{~mm}$ diameter one-joint specimen (1J).
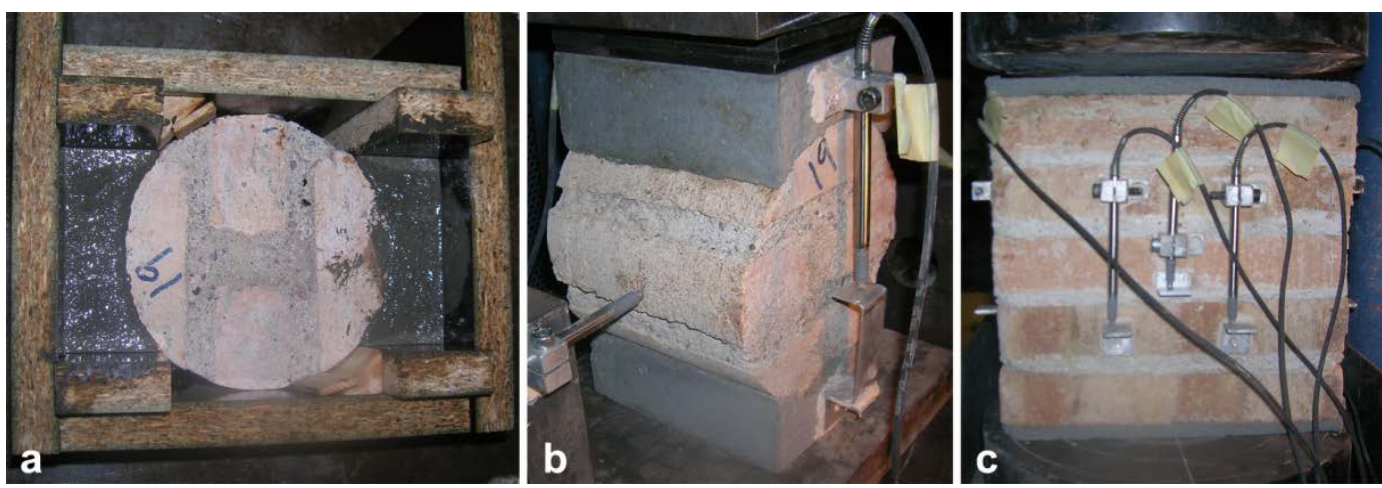

Figure 5 - Regularization of a $150 \mathrm{~mm}$ diameter core by cement mortar caps (a). Compression test setups for $3 \mathrm{~J}$ and $2 \mathrm{~J}$ cores (b) and stack-bonded prisms (c). 

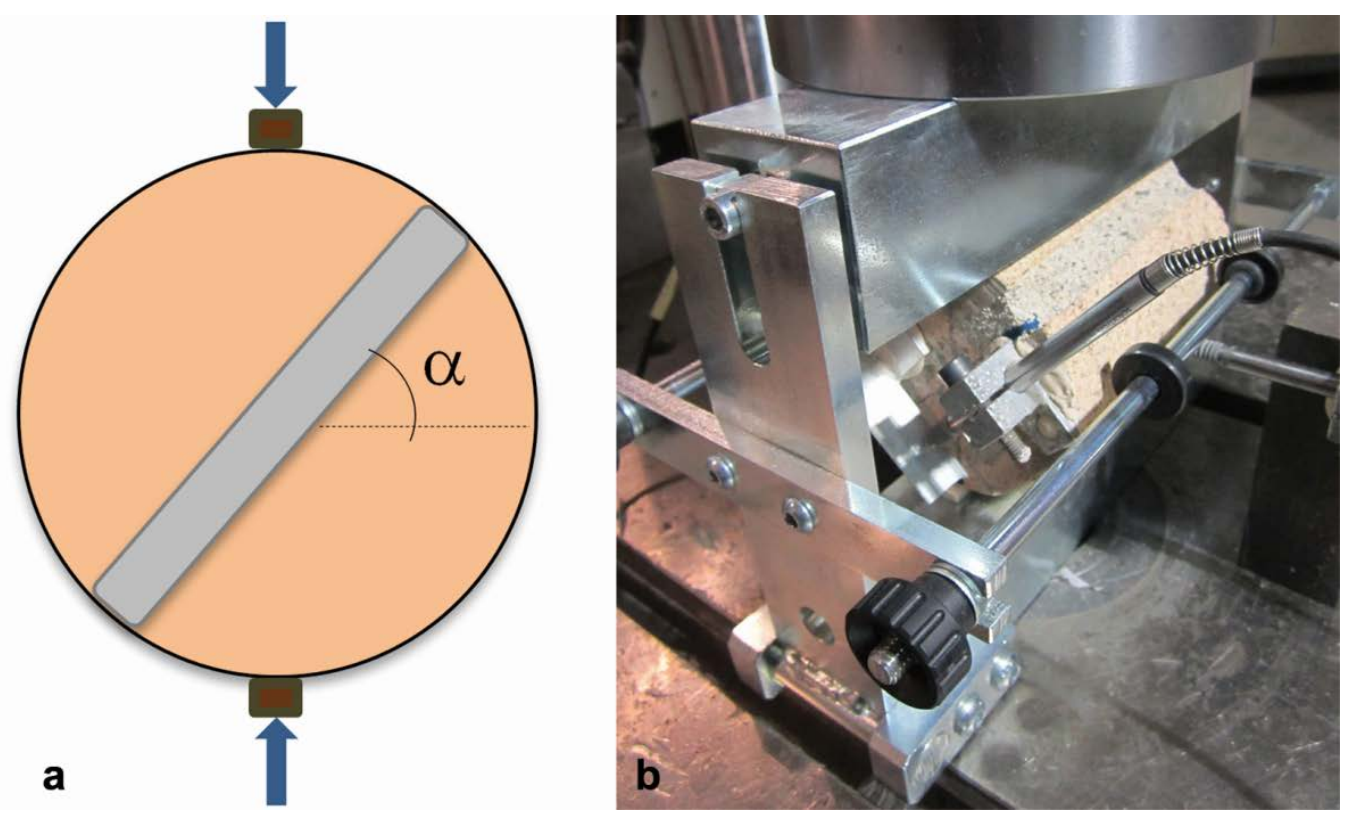

Figure 6 - Brazilian test of $1 \mathrm{~J}$ cores: a) layout and b) experimental setup.
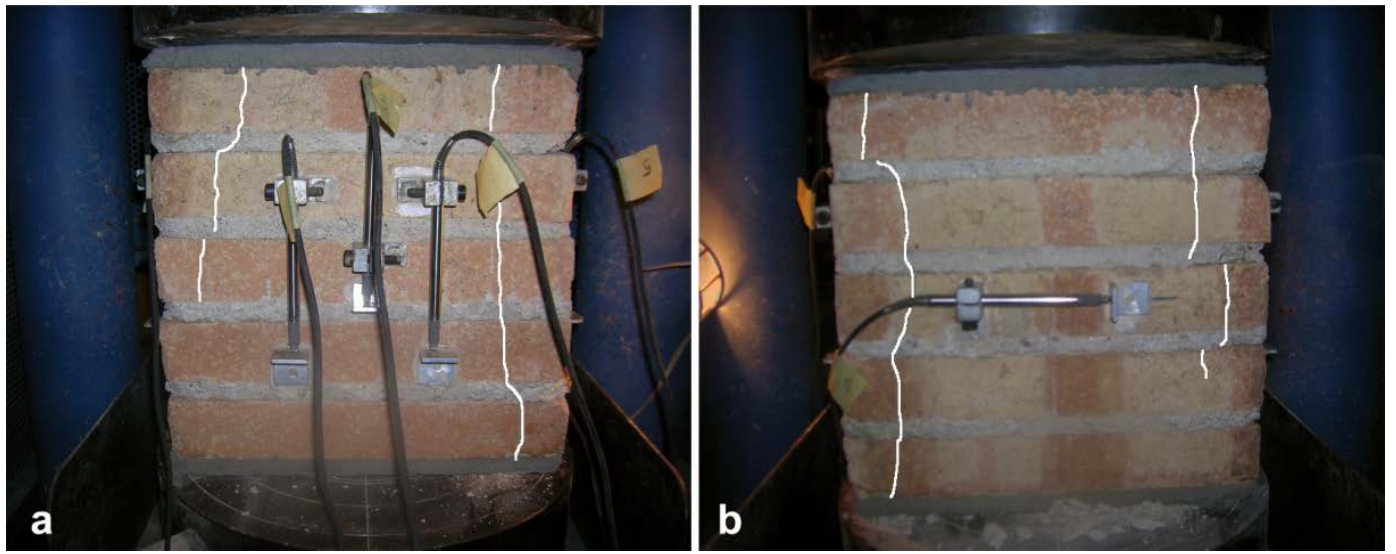

Figure 7 - Compression tests on stack-bonded prisms: a-b) cracking in specimen SP2 at failure.
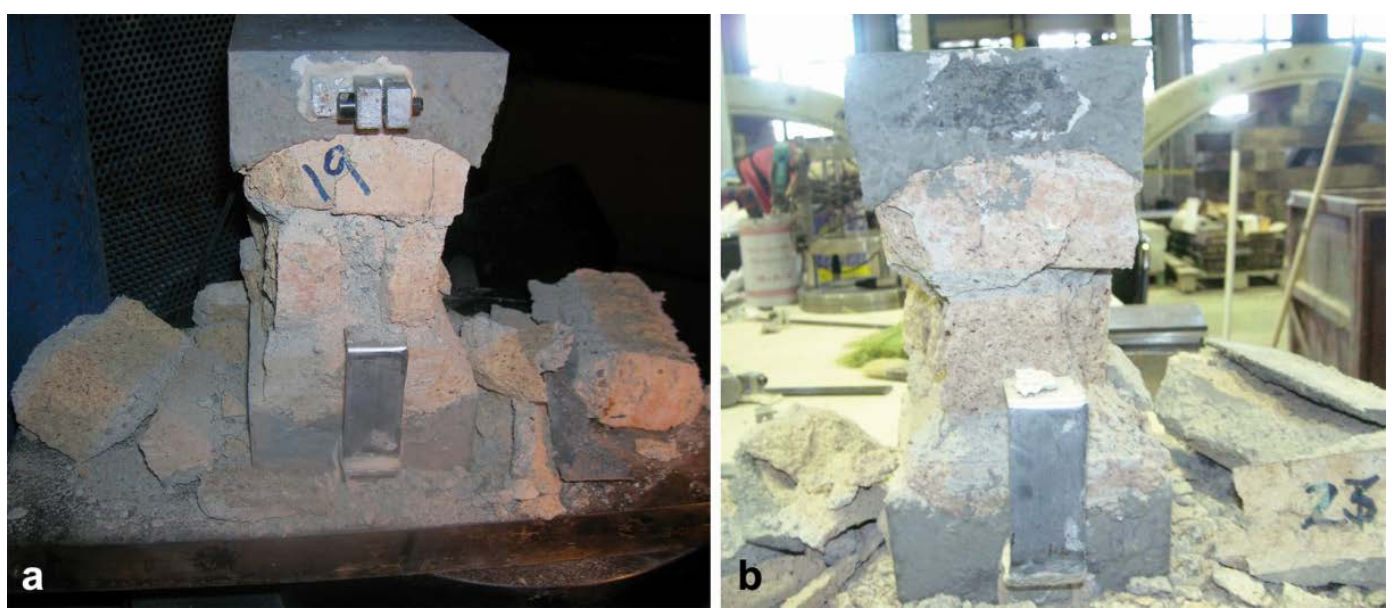

Figure 8 - Compression tests on 150 mm diameter cores: a) 3J sample and b) 2J sample after failure. 


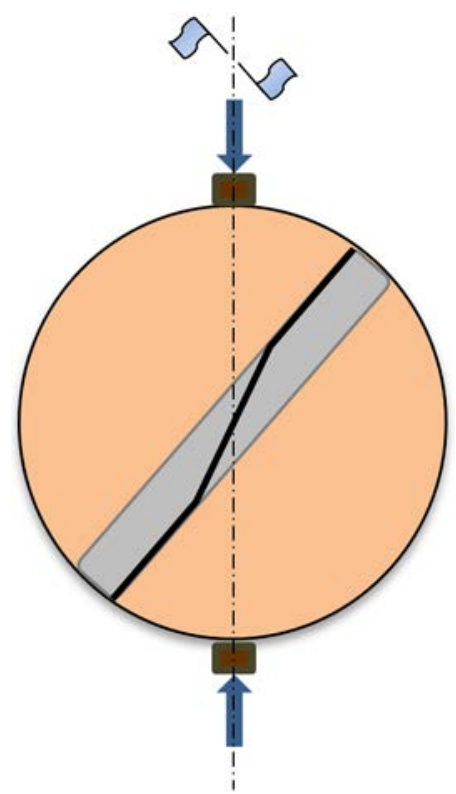

Figure 9 - The "parasymmetric” mode of failure showing central symmetry, in the Brazilian tests on $1 \mathrm{~J}$ cores.
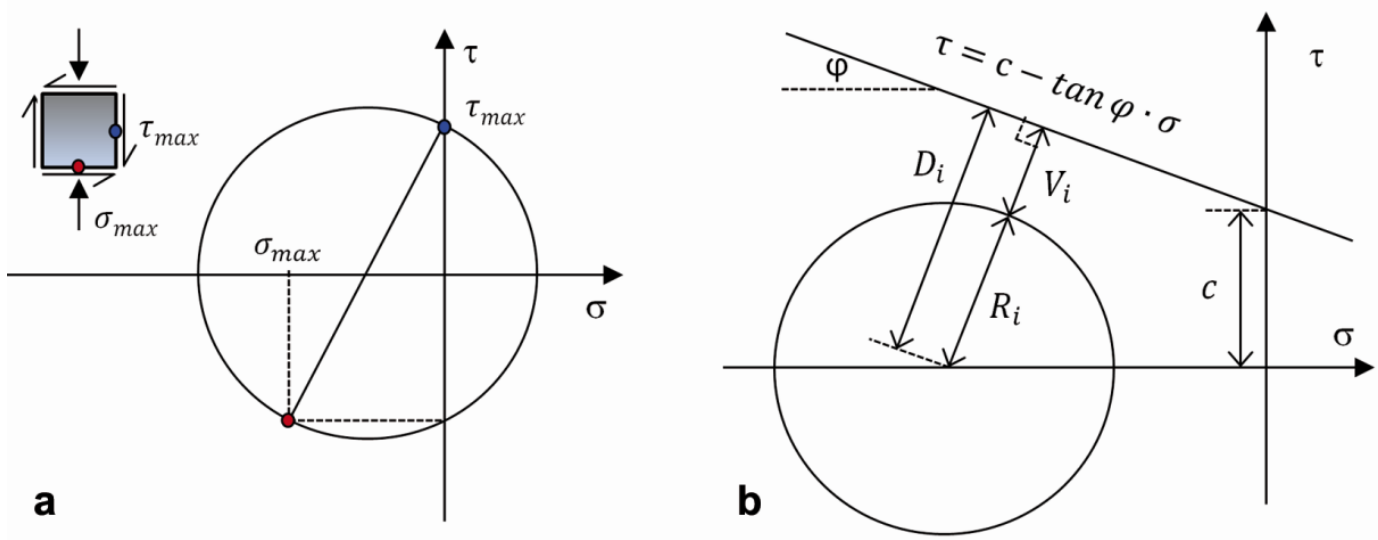

Figure 10 - Interpretation of Brazilian tests on 1J cores: a) construction of Mohr's circle representing the stress state of mortar at failure and b) least squares method used in the continuum interpretative model to evaluate the failure envelope.

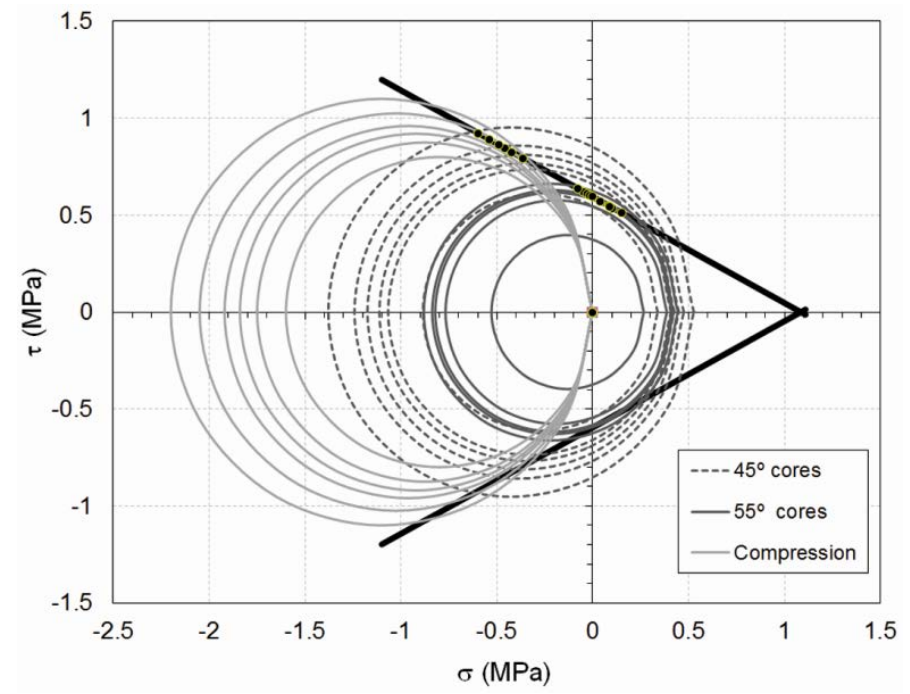

Figure 11 - Interpretation of Brazilian tests on $1 \mathrm{~J}$ cores: failure envelope obtained by the continuum model $\left(\phi=27.1^{\circ}\right.$ and $\left.c=0.62 \mathrm{MPa}\right)$. 


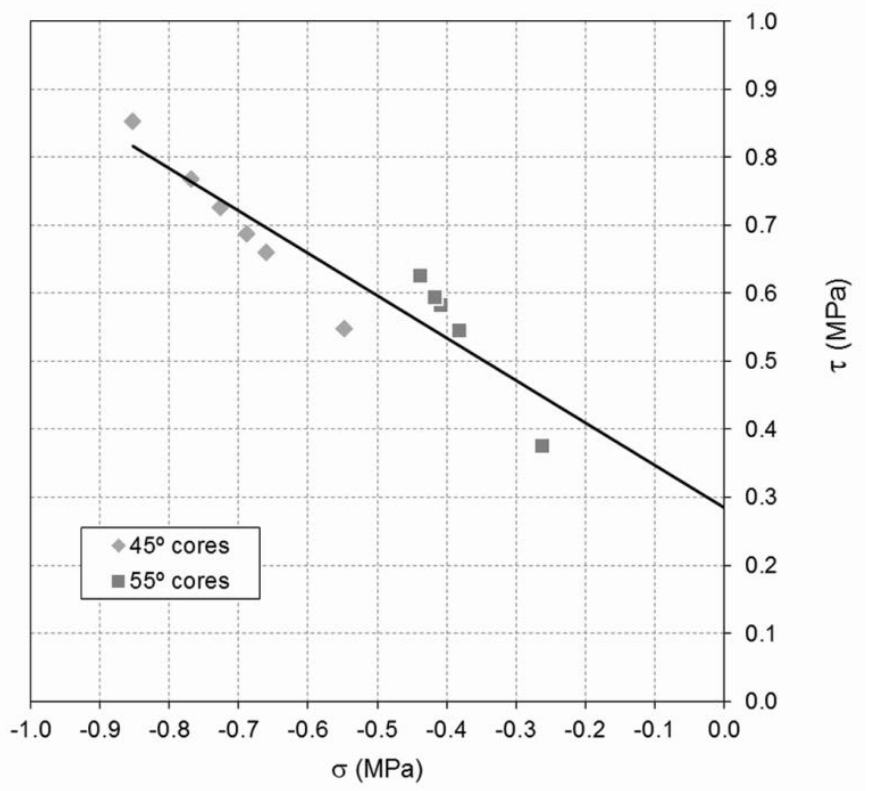

Figure 12 - Interpretation of Brazilian tests on $1 \mathrm{~J}$ cores: failure envelope obtained by the interface model $\left(\phi=31.9^{\circ}\right.$ and $\left.c=0.29 \mathrm{MPa}\right)$.

Table 1 - Experimental strengths of NHL mortar prisms, brick units and brick cores.

\begin{tabular}{|c|c|c|c|c|c|c|c|c|}
\hline \multirow{2}{*}{$\begin{array}{c}\text { Material } \\
\text { Parameter }\end{array}$} & \multicolumn{2}{|c|}{ Mortar 61 days } & \multicolumn{2}{|c|}{ Mortar 75 days } & \multicolumn{2}{|c|}{ Brick - unit } & \multicolumn{2}{|c|}{ Brick - cylinder } \\
\hline & $f_{\mathrm{mf}}(\mathrm{MPa})$ & $\mathrm{f}_{\mathrm{mc}}(\mathrm{MPa})$ & $f_{m f}(M P a)$ & $f_{m c}(M P a)$ & $f_{b f}(M P a)$ & $f_{b c}(M P a)$ & $\mathrm{f}_{\mathrm{bt}}(\mathrm{MPa})$ & $f_{b c}(M P a)$ \\
\hline & 0.56 & 1.43 & 0.99 & 1.84 & 3.97 & 25.24 & 2.58 & 23.88 \\
\hline & & 1.20 & & 1.92 & & & & \\
\hline & 0.60 & 1.90 & 0.56 & 1.60 & 3.48 & 26.27 & 2.13 & 29.31 \\
\hline & 0.64 & $\begin{array}{l}1.64 \\
1.75\end{array}$ & 0.73 & $\begin{array}{l}1.15 \\
2.05\end{array}$ & 3.59 & 24.99 & 1.82 & 22.88 \\
\hline & & 1.68 & & 2.20 & & & & \\
\hline Average & 0.60 & 1.60 & 0.76 & 1.89 & 3.68 & 25.50 & 2.18 & 25.36 \\
\hline CV (\%) & 6.7 & 15.5 & 28.5 & 11.3 & 7.0 & 2.7 & 17.4 & 13.6 \\
\hline
\end{tabular}

Table 2 - Experimental results of compression tests on stack-bonded prisms, 3J and 2J cylindrical specimens.

\begin{tabular}{|c|c|c|c|c|c|c|c|c|c|c|}
\hline \multicolumn{3}{|c|}{ Stack-bonded Prisms } & \multicolumn{4}{|c|}{ 3J samples } & \multicolumn{4}{|c|}{ 2J samples } \\
\hline Sample & $\begin{array}{l}F_{\max } \\
(\mathrm{kN})\end{array}$ & $\begin{array}{c}f_{c} \\
(\mathrm{MPa})\end{array}$ & Sample & $\begin{array}{l}\mathrm{F}_{\max } \\
(\mathrm{kN})\end{array}$ & $\begin{array}{c}\mathrm{f}_{\mathrm{C} 1} \\
(\mathrm{MPa})\end{array}$ & $\begin{array}{c}\mathrm{f}_{\mathrm{C} 2} \\
(\mathrm{MPa})\end{array}$ & Sample & $\begin{array}{l}F_{\max } \\
(\mathrm{kN})\end{array}$ & $\begin{array}{c}\mathrm{f}_{\mathrm{C} 1} \\
(\mathrm{MPa})\end{array}$ & $\begin{array}{c}\mathrm{f}_{\mathrm{C} 2} \\
(\mathrm{MPa})\end{array}$ \\
\hline SP1 & 328.28 & 8.84 & $17 a$ & 123.95 & 6.36 & 7.95 & $21 a$ & 144.41 & 7.41 & 9.26 \\
\hline SP2 & 308.96 & 8.32 & $17 \mathrm{~b}$ & 128.05 & 6.57 & 8.21 & $21 b$ & 172.07 & 8.82 & 11.03 \\
\hline SP3 & 324.83 & 8.75 & 19 & 132.42 & 6.79 & 8.49 & $23 a$ & 161.93 & 8.30 & 10.38 \\
\hline & & & $20 a$ & 141.45 & 7.25 & 9.07 & $23 b$ & 152.81 & 7.84 & 9.80 \\
\hline & & & $20 \mathrm{~b}$ & 140.64 & 7.21 & 9.02 & $24 a$ & 165.61 & 8.49 & 10.61 \\
\hline & & & & & & & $24 \mathrm{~b}$ & 150.40 & 7.71 & 9.64 \\
\hline Average & 320.69 & 8.64 & Average & 133.30 & 6.84 & 8.55 & Average & 157.87 & 8.10 & 10.12 \\
\hline CV (\%) & 3.2 & 3.2 & CV (\%) & 5.8 & 5.8 & 5.8 & CV (\%) & 6.6 & 6.6 & 6.6 \\
\hline $\begin{array}{c}\text { Charact. } \\
\text { value }\end{array}$ & 288.23 & 7.76 & $\begin{array}{c}\text { Charact. } \\
\text { value }\end{array}$ & 114.40 & 5.87 & 7.34 & $\begin{array}{c}\text { Charact. } \\
\text { value }\end{array}$ & 133.54 & 6.85 & 8.56 \\
\hline
\end{tabular}


Table 3 - Experimental results of Brazilian tests on $1 \mathrm{~J}$ cylindrical specimens: $\alpha=0^{\circ}$.

\begin{tabular}{|c|c|c|c|c|c|}
\hline ID & Before test & After test & Failure mode & $\begin{array}{l}F_{\max } \\
(\mathrm{kN})\end{array}$ & $\begin{array}{c}f_{\mathrm{t}} \\
(\mathrm{MPa})\end{array}$ \\
\hline N4 & & & & 16.13 & 0.91 \\
\hline N5 & & & & 21.79 & 0.95 \\
\hline N6 & & & & 27.54 & 1.45 \\
\hline N18 & & & & 8.83 & 0.48 \\
\hline \multicolumn{4}{|c|}{ Average } & 18.57 & 0.95 \\
\hline \multicolumn{4}{|c|}{ CV (\%) } & 43.0 & 42.1 \\
\hline
\end{tabular}

Table 4 - Experimental results of Brazilian tests on $1 \mathrm{~J}$ cylindrical specimens: $\alpha=35^{\circ}$.

\begin{tabular}{|c|c|c|c|c|c|c|}
\hline ID & Before test & After test & Failure mode & $\begin{array}{l}F_{\max } \\
(\mathrm{kN})\end{array}$ & $\begin{array}{c}\sigma_{\max } \\
(\mathrm{MPa})\end{array}$ & $\begin{array}{c}\tau_{\max } \\
(\mathrm{MPa})\end{array}$ \\
\hline N7 & & & & 13.52 & 0.95 & 0.66 \\
\hline N8 & & & & 13.83 & 0.93 & 0.65 \\
\hline N9 & & & & 12.36 & 1.01 & 0.71 \\
\hline N11 & & & & 10.73 & 0.75 & 0.53 \\
\hline N12 & & & & 14.19 & 0.97 & 0.68 \\
\hline \multicolumn{4}{|c|}{ Average } & 12.93 & 0.92 & 0.65 \\
\hline \multicolumn{4}{|c|}{ CV (\%) } & 10.9 & 10.8 & 10.8 \\
\hline
\end{tabular}


Table 5 - Experimental results of Brazilian tests on $1 \mathrm{~J}$ cylindrical specimens: $\alpha=45^{\circ}$.

\begin{tabular}{|c|c|c|c|c|c|c|}
\hline ID & Before test & After test & Failure mode & $\begin{array}{l}F_{\max } \\
(\mathrm{kN})\end{array}$ & $\begin{array}{c}\sigma_{\max } \\
(\mathrm{MPa})\end{array}$ & $\begin{array}{c}\tau_{\max } \\
(\mathrm{MPa})\end{array}$ \\
\hline N1 & & & & 12.74 & 0.77 & 0.77 \\
\hline N3 & & & & 11.96 & 0.73 & 0.73 \\
\hline N14 & & & & 11.52 & 0.69 & 0.69 \\
\hline N15 & & & & 14.24 & 0.85 & 0.85 \\
\hline N16 & & & & 10.91 & 0.66 & 0.66 \\
\hline N19 & & & & 9.20 & 0.55 & 0.55 \\
\hline \multirow{2}{*}{\multicolumn{4}{|c|}{$\begin{array}{l}\text { Average } \\
\text { CV (\%) }\end{array}$}} & 11.76 & 0.71 & 0.71 \\
\hline & & & & 14.5 & 14.6 & 14.6 \\
\hline
\end{tabular}

Table 6 - Experimental results of Brazilian tests on $1 \mathrm{~J}$ cylindrical specimens: $\alpha=55^{\circ}$.

\begin{tabular}{|c|c|c|c|c|c|c|}
\hline ID & Before test & After test & Failure mode & $\begin{array}{l}F_{\max } \\
(\mathrm{kN})\end{array}$ & $\begin{array}{c}\sigma_{\max } \\
(\mathrm{MPa}) \\
\end{array}$ & $\begin{array}{r}\tau_{\max } \\
(\mathrm{MPa}) \\
\end{array}$ \\
\hline N2 & & & & 8.44 & 0.41 & 0.58 \\
\hline N10 & & & & 7.89 & 0.44 & 0.63 \\
\hline $\mathrm{N} 13$ & & & & 7.69 & 0.38 & 0.55 \\
\hline N17 & & & & 8.75 & 0.42 & 0.59 \\
\hline
\end{tabular}




\begin{tabular}{|c|c|c|c|c|}
\hline N2O & & 5.54 & 0.26 & 0.38 \\
\hline \multirow{2}{*}{\multicolumn{2}{|c|}{$\begin{array}{c}\text { Average } \\
\text { CV (\%) }\end{array}$}} & 7.66 & 0.38 & 0.54 \\
\hline & & 16.4 & 18.2 & 18.2 \\
\hline
\end{tabular}

